\title{
Over-expression of microRNA-494 up-regulates hypoxia-inducible factor-1 alpha expression via PI3K/Akt pathway and protects against hypoxia-induced apoptosis
}

\author{
Guixiang Sun ${ }^{1}$, Yanni Zhou', Hongsheng Li ${ }^{1}$, Yingjia Guo ${ }^{1,2}$, Juan Shan ${ }^{1,2}$, Mengjuan Xia ${ }^{1}$, Youping Li ${ }^{1,3}$, \\ Shengfu Li ${ }^{1}$, Dan Long ${ }^{1}$ and Li Feng ${ }^{1,2^{*}}$
}

\begin{abstract}
Background: Hypoxia-inducible factor-1 alpha (HIF-1a) is one of the key regulators of hypoxia/ischemia. MicroRNA-494 (miR-494) had cardioprotective effects against ischemia/reperfusion (I/R)-induced injury, but its functional relationship with HIF-1a was unknown. This study was undertaken to determine if miR-494 was involved in the induction of HIF-1a.

Results: Quantitative RT-PCR showed that miR-494 was up-regulated to peak after 4 hours of hypoxia in human liver cell line L02. To investigate the role of miR-494, cells were transfected with miR-494 mimic or miR-negative control, followed by incubation under normoxia or hypoxia. Our results indicated that overexpression of miR-494 significantly induced the expression of p-Akt, HIF-1a and HO-1 determined by qRT-PCR and western blot under normoxia and hypoxia, compared to negative control $(p<0.05)$. While LY294002 treatment markedly abolished miR-494-inducing Akt activation, $\mathrm{HIF-1a}$ and $\mathrm{HO}-1$ increase under both normoxic and hypoxic conditions $(p<0.05)$. Moreover, apoptosis detection using Annexin $\mathrm{V}$ indicated that overexpression of miR-494 significantly decreased hypoxia-induced apoptosis in L02 cells, compared to control ( $p<0.05)$. MiR-494 overexpression also decreased caspase-3/7 activity by 1.27 -fold under hypoxia in L02 cells.
\end{abstract}

Conclusions: Overexpression of miR-494 upregulated HIF-1a expression through activating PI3K/Akt pathway under both normoxia and hypoxia, and had protective effects against hypoxia-induced apoptosis in L02 cells. Thus, these findings suggested that miR-494 might be a target of therapy for hepatic hypoxia/ischemia injury.

Keywords: MicroRNA-494, Hypoxia-inducible factor-1 alpha, PI3K/Akt, Apoptosis, L02 cells

\section{Background}

MicroRNAs (miRNAs) are small non-coding RNAs with the length of 21- to 25-nucleotides that posttranscriptionally regulate the expression of target genes, and play important roles in various biological processes, including development, differentiation, proliferation, and apoptosis $[1,2]$. Several studies have suggested that alterations of

\footnotetext{
* Correspondence: feng31@sohu.com

${ }^{1}$ Key Laboratory of Transplant Engineering and Immunology of Health Ministry of China, West China Hospital, Sichuan University, Chengdu 610041, Sichuan, Province, PR China

${ }^{2}$ Regenerative Medicine Research Center, West China Hospital, Sichuan University, Chengdu, Sichuan, Province, PR China

Full list of author information is available at the end of the article
}

their expression may paly a role in the regulation of the cellular response to hypoxia [3-6].

Hypoxia availability affects cells and tissues during normal embryonic development and pathological conditions such as myocardial infarction, inflammation and tumorigenesis. Hypoxia inducible factor-1 (HIF-1) is recognized as the master transcription factor consisting of a constitutively expressed HIF-1 $\beta$ subunit and an oxygen-regulated HIF- $1 \alpha$ subunit in response to hypoxia [7]. In normoxia, HIF- $1 \alpha$ is maintained at lower level by proteasomal degradation [8]. During hypoxia the degradation of HIF-1 $\alpha$ is inhibited, and then HIF- $1 \alpha$ heterodimerizes with HIF-1 $\beta$ and translocates to the nucleus [7]. HIF- $1 \alpha / \beta$ dimer binds to hypoxia response elements (HREs) and activates target 
genes transcription, including heme oxygenase-1 (HO-1), erythropoietin (EPO), vascular endothelial growth factor (VEGF), and various glycolytic enzymes that contribute to adaptation to hypoxia and/or ischemia [9]. Therefore HIF$1 \alpha$ plays a key role in hypoxic/ischemic response.

Recent studies indicate that miRNAs play important roles in hypoxia/ischemia [3,10-16]. MiR-494 has been reported to be significantly increased in ex vivo ischemia/reperfusion (I/R) mouse hearts [16]. Moreover, miR-494 has cardioprotective effects against ischemia/reperfusion-induced injury by targeting both proapoptotic proteins (PTEN, ROCK1, CaMKIII) and antiapoptotic proteins (FGFR2 and LIF) to active the Akt-mitochondrial signaling pathway [16]. Obviously, HIF- $1 \alpha$ plays an important role in hypoxia and/or ischemia conditions. Studies have shown that Akt can augment HIF-1 $\alpha$ expression by increasing its translation under both normoxic and hypoxic conditions [17-19]. However, the potential link between miR-494 and HIF-1 $\alpha$ is unknown. We hypothesize that miR-494 may have a role in influencing HIF- $1 \alpha$ expression and contribute to the cellular response to hypoxia. Simultaneously, almost all previous studies about miR-494 were implemented in tumour cells or myocardial cell. The role of miR-494 in liver cell was unclear. Therefore, the present study was undertaken to investigate the influence of miR-494 on HIF- $1 \alpha$ expression and its relative mechanism in human hepatic cell line L02. We also investigated the function of miR-494 in response to hypoxia-induced apoptosis. Our results showed that miR-494 were upregulated up to peak after $4 \mathrm{~h}$ of hypoxia in the L02 human hepatic cell line. Furthermore, we found that overexpression of miR-494 increased the of expression HIF-1 $\alpha$ through activating the PI3K/Akt signaling pathway and protected against hypoxia-induced apoptosis in the immortalized hepatocyte cell line L02.

\section{Methods}

\section{Cell culture}

The L02 human hepatic cell line purchased from China Center for Type Culture Collection (Wuhan, China) was cultured in RPMI 1640 medium (Gibco) supplemented with $10 \%$ fetal bovine serum (FBS). Cells were grown under normoxic $\left(21 \% \mathrm{O}_{2}\right)$ or hypoxic $\left(1 \% \mathrm{O}_{2}\right)$ conditions at $37^{\circ} \mathrm{C} / 5 \% \mathrm{CO}_{2}$. Specially, medium was replaced with Dulbecco's modified Eagle's medium (DMEM; Gibco) without serum and glucose during hypoxia. To block PI3K/Akt signaling pathway, LY294002 (PI3K inhibitor, $30 \mu \mathrm{mol} / \mathrm{L}$; Sigma-Aldrich) was added to the culture medium.

\section{MiRNA and cell transfection}

MiR-494 mimic and the negative control were obtained from RiboBio (Guangzhou, China). The miR-494 overexpression study was performed using miR-494 mimic (200 nM) and its negative control (200 nM). Cells were cultured to 30$50 \%$ confluence, and transfected with miR-494 mimic and negative control using Lipofectamine 2000 (Invitrogen) in serum-free Opti-MEM medium (Gibco) according to the manufacturer's instruction. Cells were cultured in fresh medium containing 10\% FBS after transfection. Transfected cells were cultured for 48 hours under normoxia $\left(21 \% \mathrm{O}_{2}, 5 \% \mathrm{CO}_{2}\right.$ in a $37^{\circ} \mathrm{C}$ incubator), or grown under normoxia for 16 hours prior to exposure to hypoxia $\left(1 \% \mathrm{O}_{2}, 5 \% \mathrm{CO}_{2}\right.$ in a $37^{\circ} \mathrm{C}$ incubator $)$ for 8 hours. After hypoxia, apoptosis was analyzed using Annexin V-FITC/ PI binding staining and caspase-3/7 activity were measured by Cytomics ${ }^{\mathrm{Tm}}$ FC500 flow cytometer (Beckman Coulter, USA). Total RNAs and protein were prepared for real-time reverse transcription-polymerase chain reaction (RT-PCR) and western blot analysis.

\section{RNA extraction and real-time RT-PCR}

Total RNA was extracted from cultured cells using Trizol (Invitrogen, Carlsbad, CA). The levels of mRNAs or miRNAs were measured by real-time quantitative RTPCR (qRT-PCR) using Bio-Rad IQ5 system. For mRNA detection, reverse transcription was performed with PrimeScript $^{\text {tw }}$ RT reagent kit (TaKaRa, Dalian, China) according to the manufacturer's instructions, and real-time RT-PCR was carried out using SsoFast ${ }^{\mathrm{Tm}}$ EvaGreen Supermix kit (Bio-Rad) with Bio-Rad IQ5 real-time PCR system. The real-time PCR reaction contained: $10 \mu \mathrm{L}$ of SsoFast EvaGreen supermix, $1 \mu \mathrm{L}$ of sense primer, $1 \mu \mathrm{L}$ of anti-sense primer, $2 \mu \mathrm{L}$ of cDNA template, and $6 \mu \mathrm{L}$ of $\mathrm{H}_{2} \mathrm{O}$. The program of two step real time RT-PCR was $95^{\circ} \mathrm{C}$ for 30 seconds, followed by 40 cycles of $95^{\circ} \mathrm{C}$ for 5 seconds, and $60^{\circ} \mathrm{C}$ for 10 seconds. The relative expression level of mRNAs was normalized to that of internal control $\beta$-actin by using the $2^{-\Delta \Delta C t}$ cycle threshold method. Primer sequences were as follows:

HIF- $1 \alpha$ sense primer, 5'-CAAGAACCTACTGCTAAT GC-3'; HIF-1 $\alpha$ anti-sense primer, 5' -TTATGTATGTGGG TAGGAGATG-3'; VEGF sense primer, 5'-ACAGGGAA GAGGAGGAGATG-3'; VEGF anti-sense primer, 5'-GCT GGGTTTGTCGGTGTTC-3'; HO-1 sense primer, 5'-GC CAGCAACAAAGTGCAAGA-3'; HO-1 anti-sense primer, $5^{\prime}$-AAGGACCCATCGGAGAAGC-3'; $\beta$-actin sense primer, 5 '-AAGATCATTGCTCCTCCTG-3'; $\beta$-actin antisense primer, 5 ' -CGTCATACTCCTGCTTGCTG-3'.

To detect the level of mature miR-494, the complementary DNA (cDNA) was synthesized using PrimeScript ${ }^{\text {tm }}$ RT reagent kit (TaKaRa, Dalian, China) and miRNA-specific stemloop RT primers (RiboBio, Guangzhou, China). The $10 \mu \mathrm{L}$ of reaction contained: $2 \mu \mathrm{L}$ of $5 \times \mathrm{RT}$ buffer, $0.5 \mu \mathrm{L}$ of PrimeScript $^{\text {tm }}$ RT Enzyme Mix, $1 \mu \mathrm{L}$ of miR-494 RT primer, $1 \mu \mathrm{L}$ of total RNA ( $<500 \mathrm{ng}$ ), and $5.5 \mu \mathrm{L}$ of $\mathrm{H}_{2} \mathrm{O}$. The incubation condition was $37^{\circ} \mathrm{C}$ for 15 minutes, followed by $85^{\circ} \mathrm{C}$ for 5 seconds. Then qRT-PCR was performed with SsoFast $^{\text {ti }}$ EvaGreen Supermix kit (Bio-Rad) and Bio-Rad IQ5 real-time PCR system. The reaction contained: $10 \mu \mathrm{L}$ 
of SsoFast EvaGreen supermix, $1.5 \mu \mathrm{L}$ of forward primer, $1.5 \mu \mathrm{L}$ of reverse primer, $2 \mu \mathrm{L}$ of cDNA template, and $5 \mu \mathrm{L}$ of $\mathrm{H}_{2} \mathrm{O}$. The program was the same as that described above. Forward and reverse primers were designed from RiboBio (Guangzhou, China). U6 small nuclear RNA was used as an internal control.

\section{Protein extraction and western blot analysis}

Cells were washed twice quickly with ice-cold phosphate buffered saline (PBS) after either hypoxic or normoxic incubation, solubilized in $1 \times$ lysis buffer $[50 \mathrm{mmol} / \mathrm{L}$ Tris (pH 6.8), 2\%SDS, $10 \%$ glycerol] with protease inhibitors (Complete, EDTA-free tablets, Roche) and phosphatase inhibitors (Roche) on ice. Cell lysates were sonicated in an Ultrasonic Dismemberator on ice, followed by boiling for 5 minutes and centrifuging at $12000 \mathrm{~g}$ for 10 minutes at $4{ }^{\circ} \mathrm{C}$ and the supernatants were retained. Protein concentration was determined by a BCA Protein Assay kit (Beyotime, Shanghai, China).

For western blot, equal amounts of total protein in special condition $(40 \mu \mathrm{g}$ for hypoxic condition, $80 \mu \mathrm{g}$ for normoxic condition) were loaded for electrophpresis in sodium dodecyl sulfate-polyacrylamide (SDS) gels and then transferred to polyvinylidene fluoride microporous membranes (PVDF; Bio-Rad). After blocking [5\% non-fat dry milk in Tris-buffer saline (TBS) and 0.1\% Tween-20] for 1 hour at room temperature, the membranes were incubated with the primary antibodies overnight at $4^{\circ} \mathrm{C}$. The following antibodies were used in this study: monoclonal antibody HIF-1 $\alpha$ (1:1000; Abcam), phospho-Akt (Ser308, 1:1000) and Akt (1:1000; Cell Signaling Technology), monoclonal antibody PTEN (1:1000; R\&D), monoclonal antibody HO-1(1:1000; EPITOMICS, USA) and monoclonal antibody $\beta$-Tubulin (1:1000; CWBIO, China). The membranes were washed three times with $1 \times$ TBST, followed by incubation with HRP-conjugated anti-rabbit or anti-mouse immunoglobulin G secondary antibodies (1:2000; Cell Signaling Technology) for 1 hour at $37^{\circ} \mathrm{C}$. The membranes were detected with enhanced chemiluminescence plus reagents (Millipore) after washing. The band images were densitometrically analyzed using Quantity one software (Bio-Rid). $\beta$-Tubulin was used as an internal control.

\section{Annexin $\mathrm{V}$ and phosphatidylinositol (PI) binding staining} The assay of Annexin V and PI binding staining was performed with an Annexin V-FITC Apoptosis Detection Kit according to the manufacturer's instructions (Keygen Biotech, Nanjing, China). In short, cells after hypoxia were digested with $0.25 \%$ trypsin without EDTA, and then washed twice with cold PBS, centrifuged at $3000 \mathrm{rpm}$ for 5 minutes. Cells were resuspended in $500 \mu \mathrm{L}$ of $1 \times$ binding buffer at a concentration of $5 \times 10^{5}$ cells $/ \mathrm{mL}, 5 \mu \mathrm{L}$ Annexin V-FITC and $5 \mu \mathrm{L}$ PI were added. Cells were gently mixed and incubated for 10 minutes at $37^{\circ} \mathrm{C}$ in the dark. Transfer $400 \mu \mathrm{L}$ of cell suspension to flow tubes. Stained cells were analyzed by Cytomics ${ }^{\text {tw }}$ FC500 flow cytometer (Beckman Coulter, USA).

\section{Caspase-3/7 activity assay}

After hypoxia, caspase activity was measured with a Vybrant FAM Caspase-3 and Caspase-7 Assay Kit according to the manufacturer's instructions (Invitrogen). Briefly, cells after hypoxia were harvested and resuspended in culture media at a concentration of $1 \times 10^{6}$ cells $/ \mathrm{mL}$. $300 \mu \mathrm{L}$ of cell suspension were transferred to each centrifugal tube, $10 \mu \mathrm{L}$ of $30 \times$ FLICA working solution were added. Cells were gently mixed and incubated for 60 minutes at $37^{\circ} \mathrm{C} / 5 \% \mathrm{CO}_{2}$ in the dark, followed by twice washing with $1 \times$ wash buffer, pelleted the cells by centrifugation of $3000 \mathrm{rpm}$ for 5 minutes. Cells were resuspended in $400 \mu \mathrm{L}$ of $1 \times$ wash buffer, and then $2 \mu \mathrm{L}$ of PI were added. Cell suspension was incubated for 5 minutes on ice in the dark. $400 \mu \mathrm{L}$ of stained cells were transferred to flow tubes and analyzed on the flow cytometer.

\section{Statistical analysis}

All data were expressed as mean \pm SD. Statistical analysis was performed using double-sided Student's $t$ test or one-way ANOVA by SPSS 13.0. $P$ value less than 0.05 was considered statistically significant difference.

\section{Results}

Hypoxia-induced changes in miRNA-494 expression in human hepatic cell line L02

In the present study, we wonder about the hypoxia-induced changes in miRNA-494 expression in L02 cells. Our results

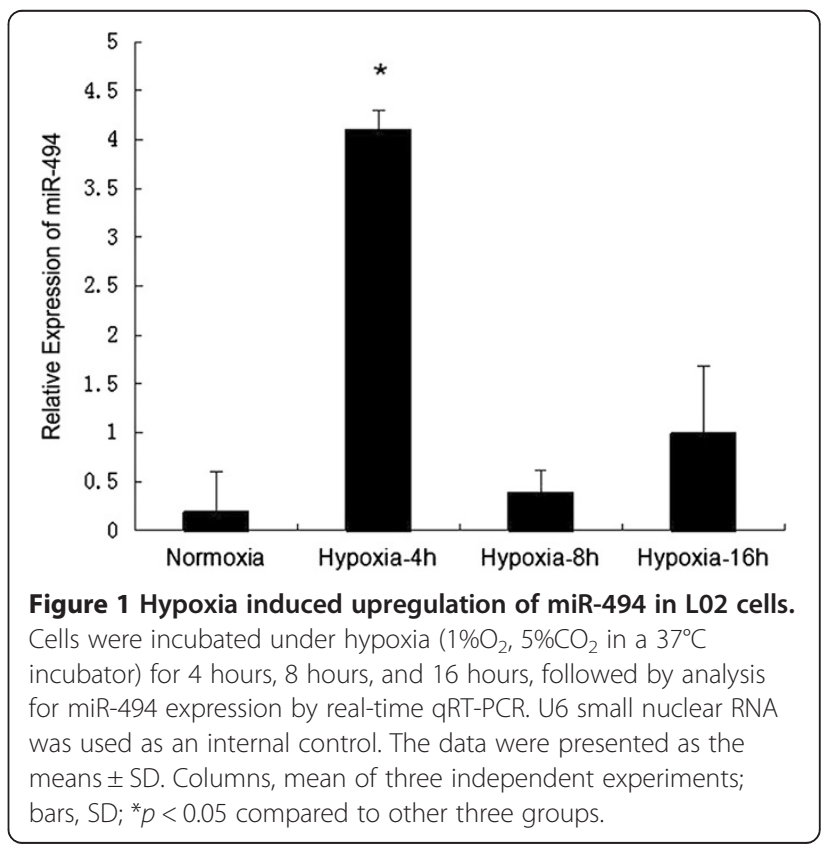


indicated that miR-494 levels were significantly upregulated after hypoxia for 4 hours, followed by decrease under further hypoxia (Figure 1). The changes were similar to that in ex vivo ischemic mouse hearts [16]. These findings indicated that alteration of miR-494 was dependent on the physiological/pathological conditions. We hypothesized that upregulation of miR-494 might represent an adaptive response to early hypoxia challenge.

\section{MiR-494 overexpression increased HIF-1a and HO-1 expression under normoxia and hypoxia}

To detect the effect of miR-494 overexpression on HIF$1 \alpha$ expression, L02 cells were transfected with miR-494 mimic or miR-negative control via Lipo2000. Comparing with the negative control group, the expression of miR494 in mimic transfection group was significantly increased after transfection for 24 hours and 48 hours, respectively (Figure 2A), indicating that miR-494 overexpression system in L02 cells was successful in technology.

Functionally, we found that overexpression of miR-494 significantly increased mRNA and protein levels of HIF$1 \alpha$ under normoxia, resulted in the subsequence expression of downstream target gene HO-1 $(p<0.05)$ (Figure 2B, C). To assess the effect of miR-494 on HIF- $1 \alpha$ under hypoxia, transfected cells were exposed to hypoxia $\left(1 \% \mathrm{O}_{2}, 5 \% \mathrm{CO}_{2}\right.$ in a $37^{\circ} \mathrm{C}$ incubator) for 8 hours. Our

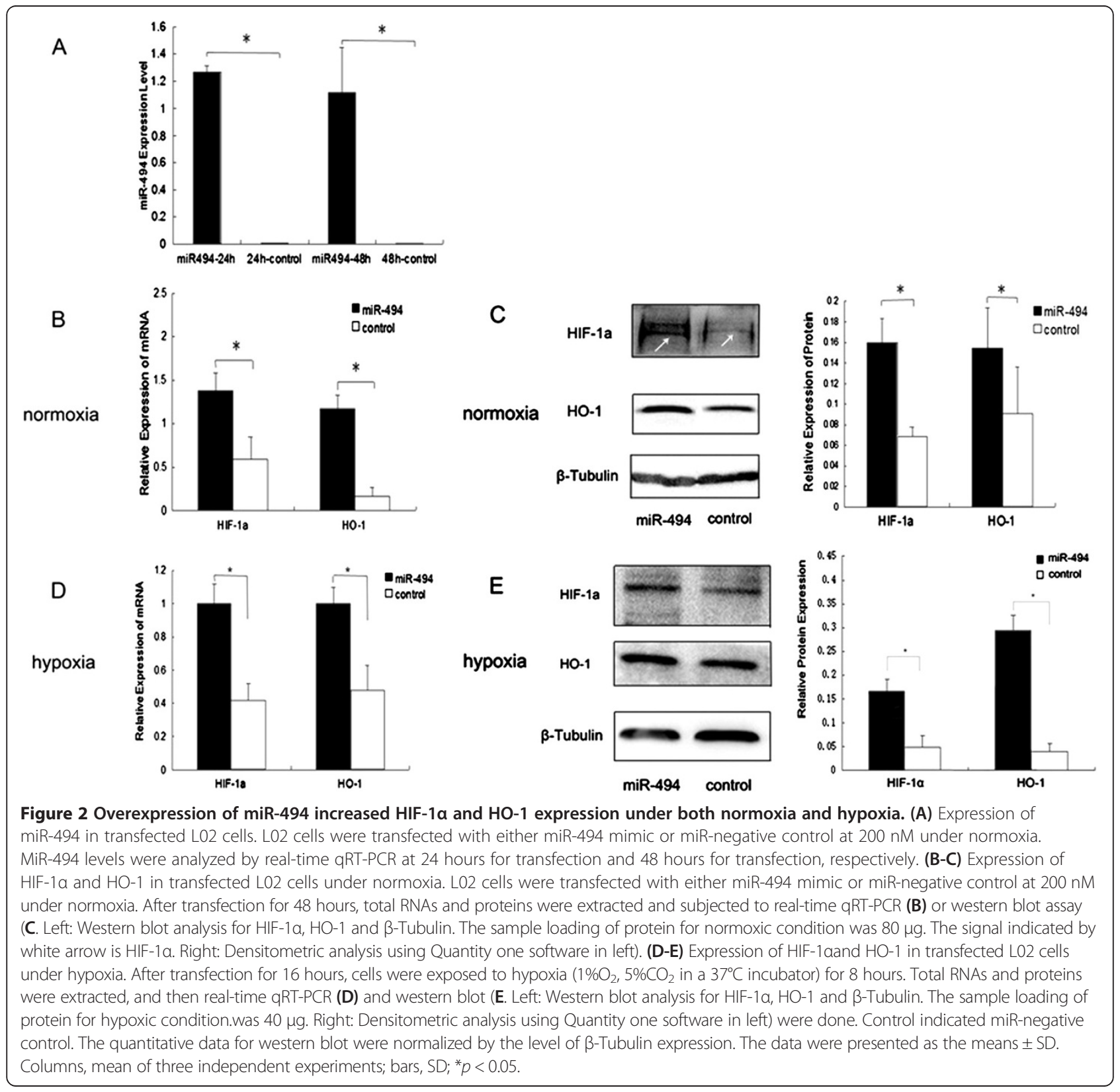


results showed that overexpression of miR-494 also significantly increased mRNA and protein levels of HIF- $1 \alpha$ and HO-1 $(\mathrm{p}<0.05)$ (Figure 2D, E). These results suggested that overexpression of miR-494 increased HIF- $1 \alpha$ and HO-1 expression levels under both normoxic and hypoxic conditions in L02 cells.

\section{MiR-494 increased HIF-1a expression through PI3K/Akt pathway}

Several studies revealed that miR-494 could target PTEN, leading to activate PI3K/Akt pathway which could augment HIF- $1 \alpha$ expression [17,20-23]. To confirm whether miR-494 increased HIF- $1 \alpha$ expression through PTEN/PI3K/Akt pathway in L02 cells, we detected proteins expression of PTEN, p-Akt, HIF- $1 \alpha$ and its target gene HO-1. We found that mRNA levels of HIF- $1 \alpha$ and HO- 1 were increased by miR-494 (Figure 3A). Overexpression of miR-494 induced Akt activation and significantly increased HIF- $1 \alpha$ and HO-1 expression under normoxia, compared to negative control $(p<0.05)$. While the significant decrease of PTEN was not observed (Figure 3B). Similarly, overexpression of miR-494 also increased mRNA levels of HIF- $1 \alpha$ and HO-1 under hypoxia (Figure 3C), and upregulated proteins expression of p-Akt, HIF- $1 \alpha$ and HO-1 in L02 cells $(p<0.05)$ (Figure 3D).

To further establish the axis of miRNA-494/p-Akt/HIF$1 \alpha$, cells were transfected with miR-494 mimic and treated with LY294002 (PI3K inhibitor, block the PI3K/Akt pathway) at $30 \mu \mathrm{M}$. LY294002 treatment inhibited miR-494inducing HIF-1 $\alpha$ and HO-1 mRNA levels (Figure 3A, C), and abolished miR-494-inducing Akt activation leading to subsequent decrease of HIF- $1 \alpha$ and HO-1 protein levels under both normoxic and hypoxic conditions $(p<0.05)$ (Figure 3B, D). These results suggested that overexpression of miR-494 could augment HIF-1 $\alpha$ expression through Akt activation in L02 cells. However, more studies are needed to determine whether miR-494 activate the Akt pathway by targeting PTEN in L02 cells.

\section{Overexpression of miR-494 protected L02 cells against hypoxia-induced apoptosis}

To determine the effect of miR-494 on hypoxia-induced apoptosis in L02 cells, transfected cells incubated under hypoxia were stained with Annexin V-FITC/PI and detected by flow cytometry (Figure 4 ). We found that most

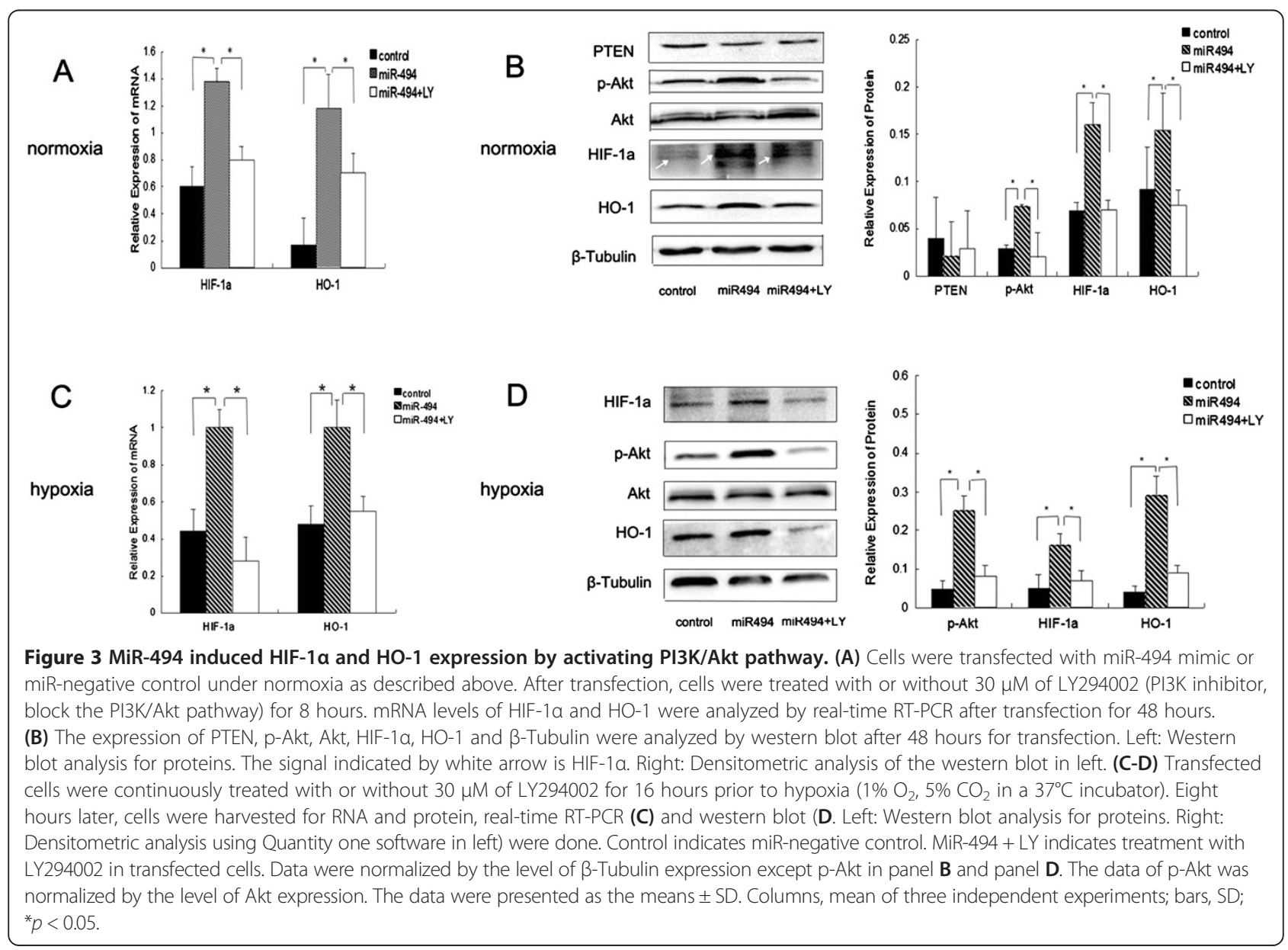



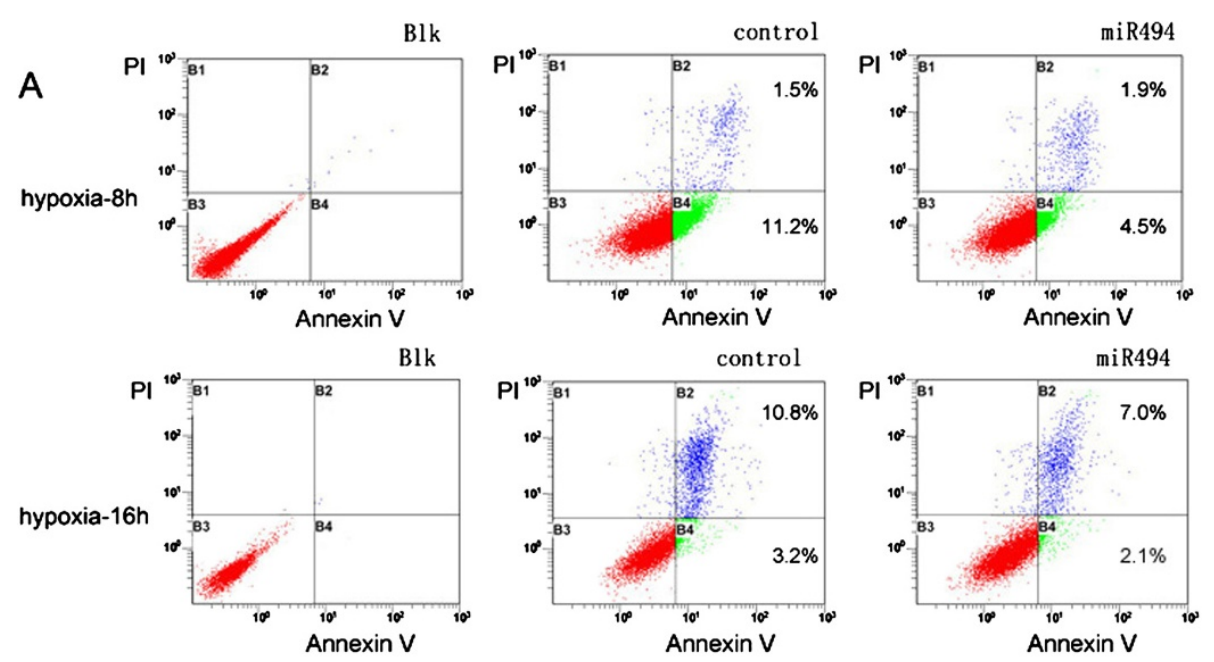

B

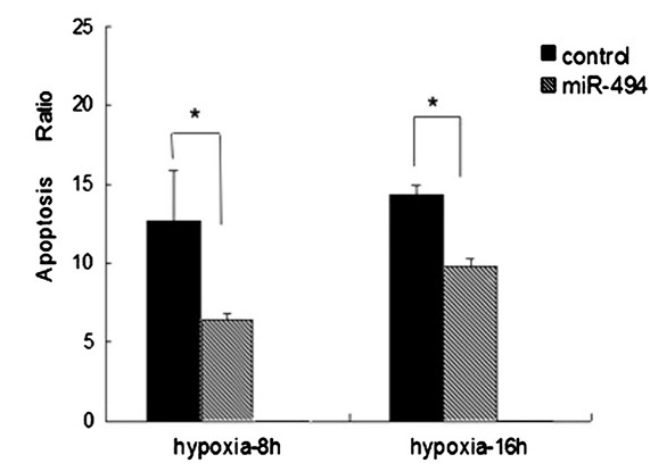

Figure 4 Effect of miR-494 on hypoxia-induced apoptosis was determined with Annexin V-FITC/PI binding staining by flow cytometry. (A) Flow cytometry results with Annexin V-TITC/PI staining. Cells were transfected with miR-494 mimic or miR-negative control as described above. After hypoxia for 8 hours (Top) or 16 hours (Bottom), cells were harvested and then apoptosis was analyzed with an Annexin V-FITC Apoptosis Detection Kit by flow cytometry. Cells were classified as healthy cells (Annexin $\mathrm{V}^{-}, \mathrm{Pl}^{-}$), early apoptotic cells $\left(\right.$Annexin $\mathrm{V}^{+}, \mathrm{Pl}^{-}$), late apoptotic cells (Annexin $\mathrm{V}^{+}, \mathrm{Pl}^{+}$), and damaged cells (Annexin $\mathrm{V}^{-}, \mathrm{PI}^{+}$). (B) The ratio of apoptosis among different experimental groups. Apoptosis ratio was early apoptosis percentage plus late apoptosis percentage. Control indicated miR-negative control. The data were presented as the means \pm SD. Columns, mean of three independent experiments; bars, SD; ${ }^{*} p<0.05$.

of apoptotic cells were at an early apoptotic state after hypoxia for $8 \mathrm{~h}$, but at a late apoptotic state after further hypoxia for $16 \mathrm{~h}$ (Figure 4A). The apoptosis ratio in miR-494 mimic group was significantly decreased comparing with control group both under hypoxia for $8 \mathrm{~h}$ and $16 \mathrm{~h}(p<0.05)$ (Figure 4B).

In addition, hypoxia-induced caspase-3/7 activity in L02 cells were assessed using a Vybrant FAM Caspase-3 and Caspase-7 Assay Kit for flow cytometry (Figure 5). After 8 hours of incubation in hypoxia, caspase-3/7 activity in miR-494mimic-transfected L02 cells decreased by 1.27 -fold compared with negative control. However, there were no statistical differences in the caspase-3/7 activity between groups (Figure 5B).

Together, these findings provided evidence that overexpression of miR-494 might protect L02 cells against hypoxia-induced apoptosis. While further study is needed to confirm this conclusion.

\section{Discussion}

Previous studies have demonstrated that miR-494 could target both proapoptotic proteins and antiapoptotic proteins to active the Akt-mitochondrial signaling pathway, leading to cardioprotective effects against ischemia/reperfusion-induced injury [16]. HIF-1 $\alpha$ plays a key role in several hypoxia-related physiologic and pathophysiologic responses, involving embryogenesis, ischemic injury and tumorigenesis [24]. However, the relationship between miR-494 and HIF- $1 \alpha$ has not been explored. Our study is first to reveal the role of overexpression of miR-494 in regulating HIF- $1 \alpha$ expression in L02 cells. In this study, we have shown that overexpression of miR-494 in L02 cells increased the expression of HIF- $1 \alpha$ and its downstream gene HO-1 by activating the PI3K/Akt pathway. We found that overexpression of miR-494 had protective effects against hypoxia-induced apoptosis in L02 cells. 


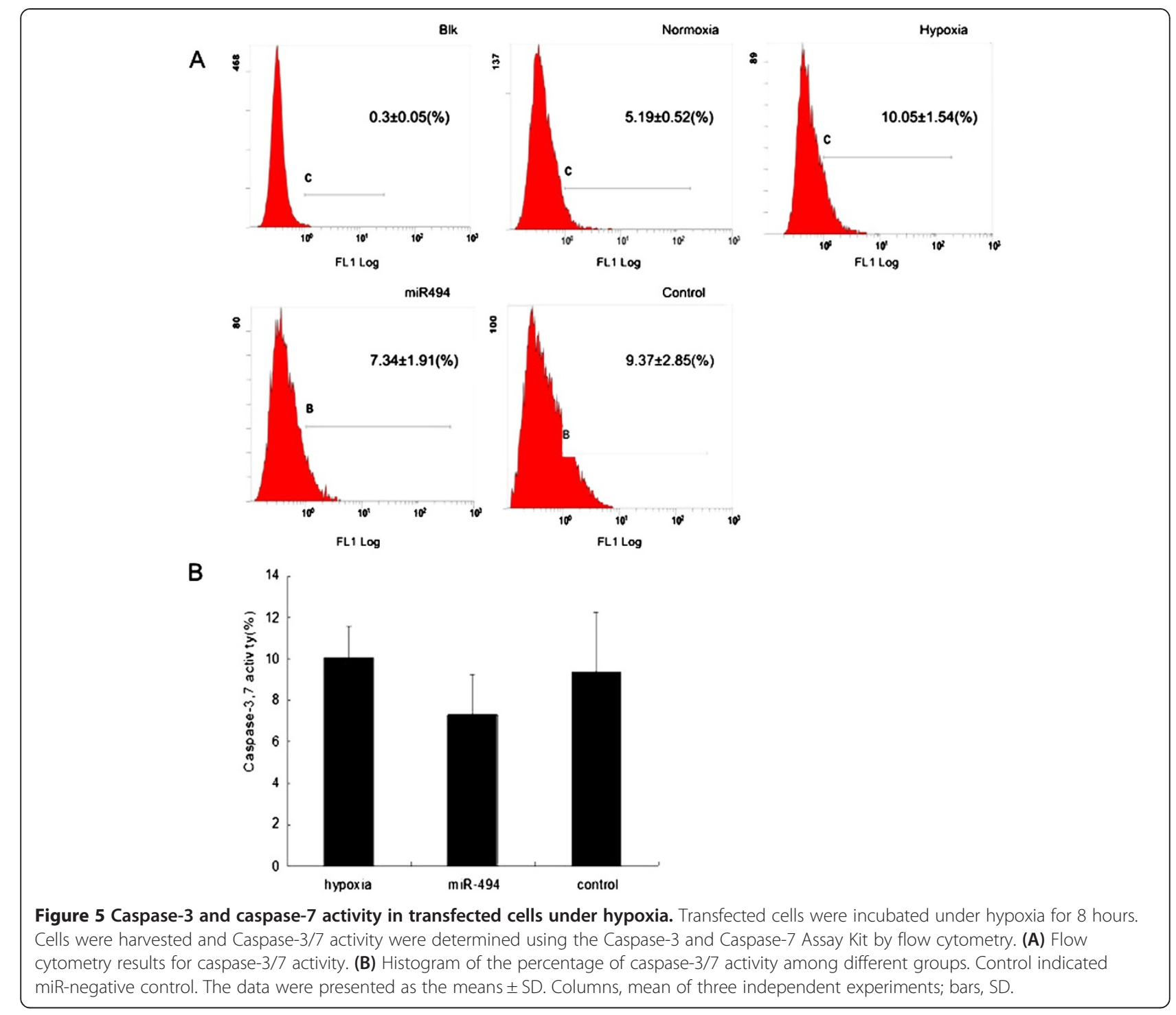

The role of HIF- $1 \alpha$ as a nuclear factor has been studied extensively [25-27]. In normoxia, HIF-1 $\alpha$ is hydroxylated by proline hydroxylase (PHD), and then recognized by the von Hippel-Lindau protein (vHL) resulting in proteosomal degradation [25]. This process is inhibited during hypoxia. HIF-1 $\alpha$ can move into the nucleus to form an active complex with HIF- $1 \beta$ and $C B P / p 300$, resulting in transcription of target genes [7]. Several regulators and mechanisms regulate the stability and activity of HIF- $1 \alpha$ protein. Recent studies indicate that miRNAs play important roles in hypoxic adaptation [2]. Many miRNAs that regulate the expression of HIF- $1 \alpha$ directly or indirectly are detected, such as miR-210, miR-519c, miR-20a and miR-21 $[3,11,15,19,28]$. One specific microRNA, miR-494 has been studied in cancer research and got more and more attention [20,29-31]. While several miRs profiling studies revealed that miR494 was downregulated in animal ischemic/hypertrophic hearts [32,33], Xiaohong Wang et al. reported that miR494 levels were increased in ex vivo I/R mouse hearts [16]. In present study, we found that miR-494 was upregulated in L02 cells during hypoxia (Figure 1), which might represent an adaptive response to hypoxia challenge. Though miR-494 was significantly increased during hypoxia for 4 hours in L02 cells. Transfected cells were exposed to hypoxia for 8 hours in our following study, because there was a more obvious difference of HIF-1 $1 \alpha$ expression after 8 hours of hypoxia between miR-494 mimic group and miR-negative control group (data not shown).

We used the microRNA target prediction websites TargetScan and mcroRNA.org to predict the relationship between miR-494 and HIF-1 $\alpha$. We found that there were no targets for miR-494 in 3' UTR of HIF- $1 \alpha$. Our results also showed that overexpression of miR-494 increased the expression of HIF- $1 \alpha$ and its downstream gene HO1 under normoxia and hypoxia in L02 cells (Figure 2). It 
suggested that miR-494 induced HIF- $1 \alpha$ expression through some other pathways, not direct regulation.

Furthermore, we investigated the mechanism of miR494 regulating HIF- $1 \alpha$ in L02 cells. A series of studies have revealed that miR-494 played an important role in tumor $[23,34,35]$. miR-494 targeted PTEN resulting in the subsequent activation of the Akt pathway involved in various pathophysiologic processes, including cell apoptosis, survival, tumor metastasis, and angiogenesis [20,22,23]. It has been reported that miR-494 had cardioprotective effects against ischemia/reperfusion-induced injury through Akt activation [16]. In our study, western blot analysis results showed that overexpression of miR-494 could markedly enhance Akt phosphorylation leading to the subsequent upregulation of HIF-1 $\alpha$ and HO-1under normoxia and hypoxia, compared to control group (Figure 3). Treatment of the L02 cells with PI3K inhibitor LY294002 inhibited miR-494-inducing HIF- $1 \alpha$ and HO-1 expression (Figure 3). Taken together, we supposed that miR-494 induced HIF-1 $\alpha$ expression dependent on Akt activation. Of course, we could not exclude that other signaling molecules also contributed in miR-494-inducing HIF-1 $\alpha$ expression. Actually, our results were similar with the mechanism of miR-21-mediated HIF- $1 \alpha$ expression that overexpression of miR-21 increased HIF-1 $\alpha$ and VEGF expression by activating AKT and ERK pathway [19]. While the direct target genes of miR-494 should be demonstrated in our future study.

To further study the biological function of miR-494 in hypoxia, cell apoptosis was detected by Annexin VFITC/PI staining and caspase-3/7 activity were analyzed by flow cytometry. Annexin V-FITC could recognize the cell membrane exposure of phosphatidylserine normally restricted to the inner cell membrane in the early apoptotic stage [36]. The late apoptotic stage was assessed by measuring the DNA labeling with the PI. Our results showed that overexpression of miR-494 decreased apoptosis ratio under hypoxia comparing with negative control (Figure 4). Simultaneously, caspase-3/7 are key executioners of apoptosis, and the activities of them can reflect levels of cell apoptosis, especially for an early apoptotic state [37]. We found that caspase- $3 / 7$ activity were decreased by 1.27 -fold in miR494mimic-transfected cells (Figure 5). Unfortunately, there were no statistical significance differences $(p>0.05)$. These data suggested that miR-494 had protective effects against hypoxia-induced apoptosis in L02 cells. But more experiments were needed to confirm the conclusion.

\section{Conclusions}

In conclusion, our investigations demonstrated that overexpression of miR-494 could augment HIF-1 $\alpha$ expression through Akt activation in L02 cells for the first time. During hypoxia, overpression of miR-494 protected L02 cells against hypoxia-induced apoptosis. Our data may be useful for further relative researches and contribute to development of a new therapy for hepatic hypoxia/ischemia injury.

\section{Competing interests}

The authors declare that they have no competing interests.

\section{Authors' contributions}

GXS was responsible for the writing of the manuscript. YNZ and HSL carried out cell transfection and real-time RT-PCR experiments. YJG and JS carried out the apoptosis detection and analysis. SFL, DL and MXJ were involved in the cell culture and Western blot experiment. YPL performed the statistical analysis. LF conceived of the study, and participated in its design and coordination and helped to draft the manuscript. All authors read and approved the final manuscript.

\section{Acknowledgements}

This work was supported by National Basic Research Program of China NO. 2009CB522401 and the Natural Science Foundation of China (NSFC) NO. 81270552 .

\section{Author details}

${ }^{1}$ Key Laboratory of Transplant Engineering and Immunology of Health Ministry of China, West China Hospital, Sichuan University, Chengdu 610041, Sichuan, Province, PR China. ${ }^{2}$ Regenerative Medicine Research Center, West China Hospital, Sichuan University, Chengdu, Sichuan, Province, PR China. ${ }^{3}$ Chinese Cochrane Centre, Chinese Evidence-Based Medicine Centre, West China Hospital, Sichuan University, Chengdu, Sichuan, Province, PR China.

Received: 11 September 2013 Accepted: 19 December 2013

Published: 23 December 2013

\section{References}

1. Shivdasani RA: MicroRNAs: regulators of gene expression and cell differentiation. Blood 2006, 108(12):3646-3653.

2. Bartel DP: MicroRNAs:genomics, biogenesis, mechanism, and function. Cell 2004, 116:281-297.

3. Chan SY, Loscalzo J: MicroRNA-210: a unique and pleiotropic hypoxamir. Cell Cycle 2010, 9(6):1072-1083.

4. Loscalzo J: The cellular response to hypoxia: tuning the system with micorRNAs. J Clin Invest 2010, 120(11):3815-3817.

5. Kulshreshtha R, Ferracin M, Wojcik SE, Garzon R, Alder H, Agosto-Perez FJ, Davuluri R, Liu CG, Croce CM, Negrini M, Calin GA, Ivan M: A mcroRNA signature of hypoxia. Mol Cell Biol 2007, 27:1859-1867.

6. Kulshreshtha R, Davuluri RV, Calin GA, Ivan M: A microRNA component of the hypoxic response. Cell Death Differ 2008, 15:667-671.

7. Adams JM, Difazio LT, Rolandelli RH, Luján JJ, Haskó G, Csóka B, Selmeczy Z, Németh ZH: HIF-1: a key mediator in hypoxia. Acta Physiol Hung 2009, 96(1):19-28

8. Huang LE, Gu J, Schau M, Bunn HF: Regulation of hypoxia-inducible factor 1 ais mediated by an O2-dependant degradation domain via the ubiquitin-proteasome pathway. Proc Natl Acad Sci 1998, 95:7987-7992.

9. Pagé EL, Robitaille GA, Pouysségur J, Richard DE: Induction of hypoxiainducible factor-1alpha by transcriptional and translational mechanisms. J Biol Chem 2002, 277:48403-48409.

10. Crosby ME, Kulshreshtha R, Ivan M, Glazer PM: Micro-RNA regulation of DNA repair gene expression in hypoxic stress. Cancer Res 2009, 69:1221-1229.

11. Cha ST, Chen PS, Johansson G, Chu CY, Wang MY, Jeng YM, Yu SL, Chen JS, Chang KJ, Jee SH, Tan CT, Lin MT, Kuo ML: MicroRNA-519c suppresses hypoxia-inducible factor-1alpha expression and tumor angiogenesis. Cancer Res 2010, 70:2675-2685.

12. Yamakuchi M, Lotterman CD, Bao C, Hruban RH, Karim B, Mendell JT, Huso D, Lowenstein CJ: P53-induced microRNA-107 inhibits HIF-1 and tumor angiogenesis. Proc Natl Acad Sci U S A 2010, 107:6334-6339.

13. Rane S, He M, Sayed D, Vashistha H, Malhotra A, Sadoshima J, Vatner DE, Vatner SF, Abdellatif M: Downregulation of miR-199a derepresses hypoxia-inducible factor-1alpha and Sirtuin 1 and recapitulates hypoxic preconditioning in cardiac myocytes. Circ Res 2009, 104(7):879-886.

14. Ghosh G, Subramanian IV, Adhikari N, Zhang X, Joshi HP, Basi D, Chandrashekhar YS, Hall JL, Roy S, Zeng Y, Ramakrishnan S: Hypoxiainduced microRNA-424 expression in human endothelial cells regulates 
HIF-a isoforms and promotes angiogenesis. J Clin Invest 2010, 120(11):4141-4154.

15. Taguchi A, Yanagisawa K, Tanaka M, Cao K, Matsuyama Y, Goto H, Takahashi T: Identification of hypoxia-inducible factor-1alpha as a novel target for miR-17-92 microRNA cluster. Cancer Res 2008, 68(14):5540-5545.

16. Wang X, Zhang X, Ren XP, Chen J, Liu H, Yang J, Medvedovic M, Hu Z, Fan GC: MicroRNA-494 targeting both proapoptotic and antiapoptotic proteins protects against ischemia/reperfusion-induced cardiac injury. Circulation 2010, 122:1308-1318.

17. Pore N, Jiang Z, Shu HK, Bernhard E, Kao GD, Maity A: Akt1 activation can augment hypoxia-inducible factor-1a expression by increasing protein translation through a mammalian target of rapamycin-independent pathway. Mol Cancer Res 2006, 4:471-479.

18. Zundel W, Schindler C, Haas-Kogan D, Koong A, Kaper F, Chen E, Gottschalk $A R$, Ryan HE, Johnson RS, Jefferson AB, Stokoe D, Giaccia AJ: Loss of PTEN facilitates HIF-1-mediated gene expression. Gene Dev 2000, 14:391-396.

19. Liu LZ, Li C, Chen $Q$, Jing Y, Carpenter R, Jiang Y, Kung HF, Lai L, Jiang BH: MiR-21 induced angiogenesis through AKT and ERK activation and HIF-1a expression. PLoS One 2011, 6(4):e19139.

20. Liu Y, Lai L, Chen Q, Song Y, X U S, Ma F, Wang X, Wang J, Yu H, Cao X, Wang Q: MicroRNA-494 is Required for the Accumulation and Functions of Tumor-Expanded Myeloid-Derived Suppressor Cells via Targeting of PTEN. J Immunol 2012, doi:10.4049/jimmunol.1103505.

21. Jiang BH, Jiang G, Zheng JZ, Lu Z, Hunter T, Vogt PK: Phosphatidylinositol3-kinase signaling controls levels of hypoxia-inducible factor-1. Cell Growth Differ 2001, 12:363-369.

22. Liu L, Jiang $Y$, Zhang $H$, Greenlee AR, Han Z: Overexpressed miR-494 downregulates PTEN gene expression in cells transformed by anti-benzopyrenetrans -7, 8-dihydrodiol-9, 10-epoxide. Life Sci 2010, 86:192-198.

23. Romano G, Acunzo M, Garofalo M, Di Leva G, Cascione L, Zanca C, Bolon B, Condorelli G, Croce CM: MiR-494 is regulated by ERK1/2 and modulates TRAIL-induced apoptosis in non-small-cell lung cancer through BIM down-regulation. Proc Natl Acad Sci U S A 2012, 109(41):16570-16575.

24. Semenza GL: HIF-1: mediator of physiologic and pathophysiologic responses to hypoxia. J Appl Physiol 2000, 88:1474-1480.

25. Mei YK, Taly RS, Garth P: HIF-1 regulation: not so easy come, easy go Cell 2008, 33(11):526-534.

26. Jean PP, Denis M, Martine R: Is HIF-1a a pro- or anti-apoptotic protein? Biochem Pharmacol 2002, 64:889-892.

27. Samoilenko AA: The role of hypoxia-inducible factor family (HIF) proteins in the regulation of cells physiologic responses to hypoxia. Ukr Biokhim Zh 2010, 82:5-17.

28. Poitz DM, Augstein A, Gradehand C, Ende G, Schmeisser A, Strasser RH: Regulation of the Hif-system by micro-RNA 17 and 20a - role during monocyte-to-macrophage differentiation. Mol Immunol 2013, 56(4):442-451.

29. Zhao JJ, Yang J, Lin J, Yao N, Zhu Y, Zheng J, Xu J, Cheng JQ, Lin JY, Ma X: Identification of miRNAs associated with tumorigenesis of retinoblastoma by miRNA microarray analysis. Childs Nerv Syst 2009, 25:13-20.

30. Roccaro AM, Sacco A, Chen C, Runnels J, Leleu X, Azab F, Azab AK, Jia X, Ngo HT, Melhem MR, Burwick N, Varticovski L, Novina CD, Rollins BJ, Anderson KC, Ghobrial IM: microRNA expression in the biology, prognosis, and therapy of Waldenström macroglobulinemia. Blood 2009, 113:4391-4402.

31. Yamamoto $H$, Morino $K$, Nishio Y, Ugi S, Yoshizaki T, Kashiwagi A, Maegawa $H$ : MicroRNA-494 regulates mitochondrial biogenesis in skeletal muscle through mitochondrial transcription factor A and Forkhead box j3. Am J Physiol Endocrinol Metab 2012, 303:E1419-E1427.

32. Thum T, Catalucci D, Bauersachs J: MicroRNAs: novel regulators in cardiac development and disease. Cardiovasc Res 2008, 79:562-570.

33. Yang B, Lu Y, Wang Z: Control of cardiac excitability by microRNAs. Cardiovasc Res 2008, 79:571-580.

34. Yamanaka S, Campbell NR, An F, Kuo SC, Potter JJ, Mezey E, Maitra A, Selaru FM: Coordinated effects of microRNA-494 induce $\mathrm{G}(2) / \mathrm{M}$ arrest in human cholangiocarcinoma. Cell Cyclen 2012, 11(14):2729-2738.

35. Ramachandran S, Karp PH, Osterhaus SR, Jiang P, Wohlford-Lenane C, Lennox KA, Jacobi AM, Praekh K, Rose SD, Behlke MA, Xing Y, Welsh MJ, McCray PB Jr:
Post-transcriptional Regulation of CFTR Expression and Function by MicroRNAs. Am J Respir Cell Mol Biol 2013, 49(4):544-551.

36. Vermes I, Haanen C, Steffens-Nakken H, Reutelingsperger C: A novel assay for apoptosis Flow cytometric detection of phosphatidylserine early apoptotic cells using fluorescein labelled expression on Annexin V. J Immunol Methods 1995, 184:39-51.

37. Cryns V, Yuan J: Protease to die for. Genes Dev 1998, 12(11):1551-1570.

doi:10.1186/1423-0127-20-100

Cite this article as: Sun et al:: Over-expression of microRNA-494 up-regulates hypoxia-inducible factor-1 alpha expression via PI3K/Akt pathway and protects against hypoxia-induced apoptosis. Journal of Biomedical Science 2013 20:100.

\section{Submit your next manuscript to BioMed Central and take full advantage of:}

- Convenient online submission

- Thorough peer review

- No space constraints or color figure charges

- Immediate publication on acceptance

- Inclusion in PubMed, CAS, Scopus and Google Scholar

- Research which is freely available for redistribution

Submit your manuscript at www.biomedcentral.com/submit
() Biomed Central 